\title{
Volvulus of the splenic flexure of the colon
}

S.N. Deshmukh, S.G. Agarwal, R.B. Soni

Department of Surgery, Dr. Vaishampayan Memorial Government Medical College, Solapur, Maharashtra, India

Key words: Volvulus; splenic flexure; colon

\section{Introduction:}

A volvulus is a twisting or axial rotation of a portion of bowel about its mesentery. Volvulus may be primary or secondary. A secondary volvulus is a more common variety which occurs due to actual rotation of a piece of bowel around an acquired adhesion or stoma.[1] Volvulus of the splenic flexure is a rare clinical entity. Because of its rarity here we report a case of primary splenic flexure volvulus.

\section{Case History:}

A 29- year-old, male (mentally retarded) was admitted with abdominal pain, distention, vomiting, and constipation of 2 days duration. On examination, the abdomen was grossly distended, slightly tender and bowel sounds were present. On percussion, abdomen was resonant. Rectal examination was normal. There was no history of previous abdominal surgery. Plain abdominal radiograph revealed marked elevation of both domes of the diaphragm with massively dilated large bowel coils with air fluid level in central abdomen suggesting large bowel obstruction. Laboratory parameters were unremarkable. Exploratory laparotomy by vertical midline incision revealed anticlockwise twist of splenic flexure of colon leading to mechanical large bowel obstruction. (Figure.1) The spleen was normal in position and there was no associated malrotation of the gut or congenital bands. After detorsion of volvulus, segmental resection with primary anastomosis between the transverse and descending colon was performed. Recovery was uneventful.

\section{Discussion:}

Primary splenic flexure volvulus is extremely rare with

Correspondence: S.N.Deshmukh

E-mail: santoshkumarndeshmukh@gmail.com

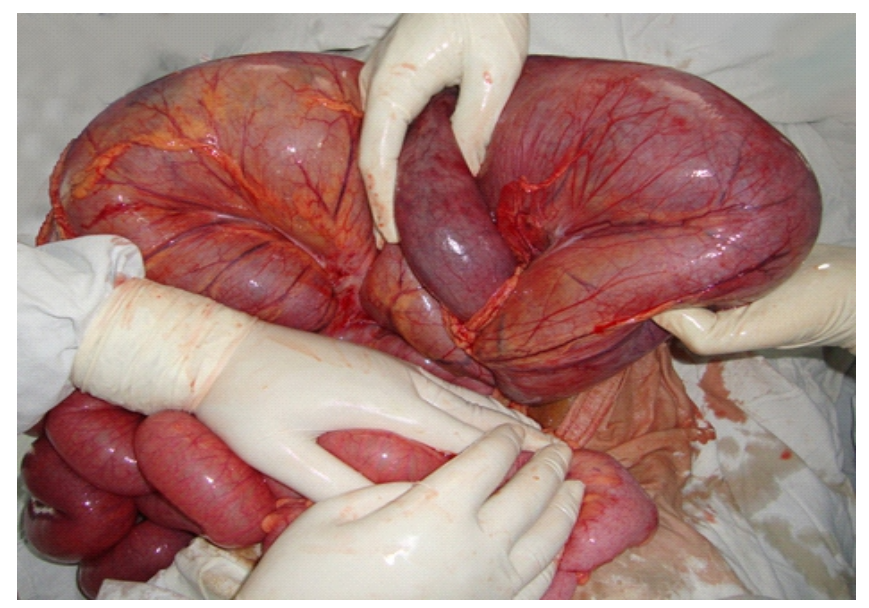

Figure 1. Anticlockwise twist of splenic flexure of colon.

an incidence of less than $2 \%$ of all colonic volvulus. It is rare because this part of large bowel has limited mobility due to the phrenicocolic, gastrocolic and splenocolic ligaments and the retroperitoneal position of the descending colon. For the splenic flexure volvulus to occur, some or all of these anatomical factors must be either congenitally deficient or altered by surgery, thus rendering the flexure unusually mobile. The presence of congenital bands or acquired adhesions have both been documented as aetiological factors.[2] In our patient there was no previous abdominal surgery but phrenicocolic, gastrocolic and splenocolic ligaments were absent.

The presentation is usually non-acute with recurrent episodes of abdominal pain, distension and vomiting. The acute presentation with features of gangrene and peritonitis is rare [3]. Due to its rarity, preoperative diagnosis is usually not suspected. Plain X-rays are less frequently diagnostic [4]. Volvulus of the splenic flexure is typically treated with resection and primary anastomosis [5]. A primary anastomosis is avoided in the presence of gangrenous bowel, perforation and peritoneal soiling, due to high risk of anastomotic leak.

Non-resectional colopexy can be tried in high-risk or elderly patients who are poor surgical candidates [3]. 
The overall mortality ranges from 16 to $33 \%$ and depends significantly on delay in diagnosis, presence of shock, feacal peritonitis and associated comorbidities [2].

\section{References}

1. Winslet MC: Intestinal obstruction. In: Williams NS, Bulstrode CJK, O'connell PR (eds): Bailey \& love's short practice of surgery. London : Hodder Arnold, 2008 ;1191-92.

2. Ballantyne GH, Brandner MD, Beart RW Jr, IIstrup DM. Volvulus of the colon. Incidence and mortality. Ann Surg
$1985 ; 202: 83-92$.

3. Mittal R, Samarasam I, Chandran S, Mathew G. Primary splenic flexure volvulus. 1 Singapore Med J 2007; 48(3):e879.

4. Narayansingh V, Raju GC. Splenic flexure volvulus. Postgrad Med J 1985;61(721):1007- 1008.

5. Havenstrite KA, Harris JA, Rivera DE. Splenic flexure volvulus in association with Chilaiditi's syndrome: report of a case. Am Surg 1999; 65:874-6.

\section{Key points:}

- Primary splenic flexure volvulus is a rare clinical entity.

- The presentation is usually non-acute with recurrent episodes of abdominal pain, distension and vomiting.

- Failure to promptly identify and treat a splenic flexure volvulus can result in colonic ischaemia, gangrene, perforation and subsequent peritonitis with high mortality rates. 